\title{
John Darzentas and Jenny Darzentas Systems Thinking in Design: Service Design and self-Services
}

\begin{abstract}
The purpose of this paper is twofold. Firstly, it seeks to use a practical real-world example to demonstrate the power of a systems thinking perspective in design, and more specifically in the design of services. It makes use of the paradigm of e-accessibility, in the application domain of publicly available self-services. Secondly, the benefits of this perspective will be discussed, through some theoretical tenets of systems thinking, such as the use of emerging properties, the law of requisite variety and notions of second order cybernetics, in terms of the richness that they offer to the conceptualisation and praxis of design in general, and service design in particular. Finally, we speculate on the implications of systems thinking to question the nature of the interdisciplinarity and even transdisciplinarity of design.
\end{abstract}

Keywords: systems thinking, service design, self-services, Design for All, accessibility, design thinking, interdisciplinarity, transdisciplinarity

\section{Introduction}

Currently we are witnessing a renewed interest and appreciation of systems thinking in a range of domains, such as biology, law, social sciences, pychology, engineering and management. More specifically for design, there is an emergent interest in the potential of systems thinking approaches to support the theory and praxis of design, as evidenced by the recent work of design researchers (e.g; Jonas, 2007, 2011; Valtonen, 2010; Sevaldson, 2010a, 2010b; Liem, 2012; Riis, 2013). This paper follows this direction and uses the vehicle of service design to try to apply a systems thinking approach in a real world exercise prompted by the problems apparent in the eAccessibility of self-services.

Broadly speaking, in line with the move to service-based economies (Maglio et al., 2006), service design deals with intangible 'products' such as the design of interactions between customers and service providers service design is by its very nature, human-centric, and therefore a prime example of ill-defined, "wicked problems". Furthermore, the service design interactions concern other stakeholders beyond the dyad provider-consumer. Each group of stakeholders involved has its own set of needs and constraints, leading to greater and greater complexity. This calls for a wider definition of design and its role. In this type of design, solutions are not designed in the traditional sense, rather designers working in service design accept that they are enablers of services rather than creators of services (Meroni \& Sangiorgi, 2011). Furthermore, design interventions need to be consonant with the 'larger picture' if they are to be acceptable.

Consideration of the 'larger picture' -and the extra layers of complexity this involvescorresponds to contemporary design thinking. There are design researchers (Norman, 2009) and design practitioners (Brown, 2008) who champion holistic approaches to design and to design education. They posit that the design of products should look beyond the use of those products, to the users and their context of use, and also to wider socio-economic and even environmental impacts. For others, the connection between the design of products and of services is part of a continuum. Forlizzi (2008) sees the move from products to services design as part of an ecology where the designer has always been motivated by the overall experience of users rather than their use of a product. Finally, the theoretical foundations of the Product Service System (PSS) from Manzini (Manzini et al., 2001; Sangiorgi, 2010) makes explicit the bridges between products and services. What can be retained is that service design forces all these considerations to the fore. It is no longer possible to ignore the complexity surrounding the design of services and design problems in general. 
Against this background, this paper presents an analysis of a particular range of services; that of self-services for the general public, where there is a strong risk of exclusion of vulnerable populations. We use this case to force the issue of acknowledging complexity and further, to emphasise the need for thinking tools to help to manage that complexity. They are urgently needed in order to avoid reductionism, which brings with it the inevitable omission of some aspects of the design problem space. Systems thinking requires working with the 'larger picture' and recognises that decomposition into smaller parts means that the important interrelationships amongst those parts will be lost. Furthermore, it seeks to accommodate the human-centric nature of problems. Thus, systems thinking carries with it not just a new way of looking at the design problem space, but arguably ways of dealing with it.

The purpose of the paper is twofold. Firstly, it aims to present some justification as to why and how systems thinking can help designers to identify and acknowledge holistically the dimensions of problem space for which they are required to design. To do this, it makes use of the paradigm of e-accessibility and of Design for All applied to the domain of publicly available self-services. This enables it to demonstrate and discuss the power of a systems thinking perspective in design, and more specifically in the design of services. Secondly, the richness of the approach is discussed, through some theoretical tenets of systems thinking, such as the embracing of complexity, the use of the emerging properties; the law of requisite variety; and notions from second-order cybernetics. In this way, we demonstrate the power that systems thinking lends to the conceptualisation and praxis of design. Finally, in the context of the evolving debate surrounding the types of competencies required by modern designers and the interdisciplinarity and even transdisciplinarity of design (Love, 2002), we posit the traction to be gained by designers using a systems thinking worldview, and the thinking tools it brings. We believe this is especially relevant, in the ever continual struggle of design educators to equip their students for new and emerging areas of design involvement such as service design, design for sustainability and design for social innovation (Jegou \& Manzini, 2008).

This paper is structured as follows: in the next section we present a background to systems thinking, as well as to service design and self-services with the attendant issues raised by considerations of e-accessibility. This leads into the main argument of the paper where we posit our view on the role of systems thinking in design. To illustrate how this might work in practice, we analyse a relevant case in service design. This is followed by a discussion of the implications that this exercise surfaces and finishes with our conclusions regarding the wider issues posed for supporting design in its theory and praxis.

\section{Background}

The ubiquity and usefulness of self-services are compromised by the problems of inaccessibility they present for many groups of people. The problems are explained and some currently proposed and implemented solutions are presented. These solutions, as we will show, offer some relief, but do not however, radically alter the situation.

\section{Systems Thinking}

Systems thinking came about in response to the failure of mechanistic thinking and vitalism to explain biological phenomena. According to systems thinking, a 'system' is a complex and highly interconnected network of parts, which exhibit synergistic properties, where the whole exceeds the sum of its parts. The living organisms are, as far their organisation is concerned, closed systems, while at the same time, as far as their energy is concerned, they are open, with incoming and outgoing energy and matter. That is, they are not 'idle' or 'immobilized' in their immediate surroundings, and are studied as a total entity. In this way, they present 
emergent properties, which cannot be deduced from their component parts (von Bertanlanffy, 1974).

The perspective of understanding the world as being composed of interconnected systems has been adopted in other domains than that of biology. Indeed, Systems Thinking, in its trajectory through time and application domains, has amalgamated other domains such as 'biology', 'information theory', 'management', 'General Systems Theory', 'cybernetics' amongst others. So called 'hard' systems theory has been used in engineering and engineering design for many decades (Sage, 1991). Systems thinking has been applied within the management and organisation disciplines (Flood \& Jackson, 1991), where it has offered new insights and ways of managing sociotechnical systems containing people, processes and technologies.

However, it is acknowledged that the real power of systems thinking is in dealing with the high complexity of ill-structured problems (Checkland, 2000) that are traditionally human-centric (Ackoff, 1974, Bausch, 2001). Systems thinking requires shifts from traditional classical decomposition or reductionist ways of doing things. It looks at relationships (rather than unrelated objects), at connectedness, at process (rather than structure), at the whole (rather than just its parts), the patterns (rather than the contents) of a system, and context. It offers a perspective which provides tools for understanding relationships between things and does not look for a single answer to a problem within the confines of a single discipline (Moore \& Kearsly, 1996/2005; Cameron \& Mengler, 2009). While understanding the whole involves understanding the parts, it also requires an examination of the inter-relations between the parts. In this way, systems present emergent properties, which cannot be deduced from their component parts.

A correspondence with the domain of design can be seen in the transition from the socalled 'first generation' of design thinkers (Bayarzit, 2004) who were searching to give 'scientific rigour' to design, to the next generation who were well able to articulate the particular aptitudes that designers possess, that were beyond the bounds of 'scientific rationality'. As Cross (1994) noted, designers are able to "produce novel unexpected solutions, tolerate uncertainty, work with incomplete information" (1994, p. 41). Currently, a number of contemporary design researchers are promoting the use of systems thinking in their research, teaching and practice (Arnellos, Spyrou \& Darzentas, 2006, 2007; Charnley \& Lemon, 2011; Darzentas \& Darzentas, 2013; Jonas, 2007; 2011; Sevaldson, 2010a, 2010b; Valtonen, 2010). In each case, the design problems represent complex domains, such as 'sustainable design' (Charnley \& Lemon, 2011); organisational design, including complex problem formulation and systems redesign (Pourdehnad et al., 2011) the nature of design (Nelson \& Stolterman, 2002, 2012); information technology and innovation in general (Dubberly, 2008).

Systems thinking, that by its very nature, welcomes -and even requires -complexity, accords well with present day design problems that are concerned with contemporary issues such as sustainability, stewardship and social innovation and exhibit a high degree of complexity due to their human-centric focus. In particular, services represent such a complex domain, where no one discipline can singlehandedly deal with the issues involved. Service science researchers from the management disciplines are now actively promoting the use of systems thinking in addition to other tools ( $\mathrm{Ng}$ et al., 2009, 2012; Mele et al., 2010).

\section{Services and Service Design}

Services have moved from being a peripheral activity in a manufacturing centred economy, to an engine for growth and society-driven innovation. This transformation has been fully recognised with a flourishing of service innovation and service research studies aimed at 
deepening the understanding, and supporting the development of, services both as a sector and as a concept (Maglio et al., 2006).

Realising that services represent complex interactions that no one discipline can model (Glushko, 2010), an initiative was started to bring disciplines together under the umbrella of Service Science, Management and Engineering (SSME) (Maglio et al., 2006). Known more commonly as 'Service Science' its aims are to integrate findings from these different disciplines to achieve better understandings, tools and techniques for creating innovative services.

Vargo and Lusch (2004) argue that services require a change of perspective or 'logic'. having been based on a model of exchange they term 'goods-dominant logic'. In this view, services are being treated as products, as tangible resources with intrinsic values and with a basis in transaction. That is, the customer obtains the goods/services in exchange for money, and that is the end of the interaction with the provider. In contrast, 'service dominant logic' (SDL) describes services as intangible resources. Providers do not provide value, but 'value propositions'; that is customers decide whether or not to make value out of those propositions or offerings, in effect they 'co-create' with the service providers.

Starting from their initial focus on service interactions and experiences, service design research and practice have entered more strategic and transformational roles, engaging with issues of organisational change, system design, sustainability and social change, among others (Gloppen, 2011). Fundamentally, designers are well placed by their training to be able to contribute in this area where the outcomes are not known, or even predicted, by service providers. The task of the service designers, broadly speaking, is to enable co-creation of value between all stakeholders, by helping to create the right conditions for interactions and relationships to emerge and evolve (Meroni \& Sangiorgi, 2011).

\section{Self-services}

In the study of services, self-services are often viewed as a particular class of touchpoint in the overall service, or an alternative means of accessing a service from a provider. For instance, if the service is to provide money, it can be obtained from a teller in the bank or from an automated teller machine (ATM). In this view, the self-service version differs from the human-mediated version, in that contact with the service provider is carried out by means of a machine or an online application. Meuter et al. (2000) defined self-service technologies as technological interfaces that allow customers to access or produce services independent of direct service employee involvement.

For Scupola (2011) self-services are a first step in an evolution of services that begins with self-service terminals, move on to e-services, and now are in a phase of mobile or ' $\mathrm{m}$ services' meaning those accessed on the move via smart phones and other internet enabled devices. This is a useful technology-oriented view that places early kiosks as non-internet connected transaction machines, and the latest self service incarnations as mobile enabled transactions affording a high degree of interactivity between service providers and patrons.

Economists and innovatorssee self-service as an economic revolution (Castro et al, 2010), capable of changing the nature of exchange and increasing customer participation. They believe that the gains for efficiency and productivity in automating 'front office' aspects of business and government that deal with customers are substantial. Self-service then necessarily means that customers have to take a more active part in accessing and using the service than they would in a more traditional based face to face encounter, where it was, for instance, not unknown for clerks to fill in forms on behalf of clients.

To date, the service research community distinguishes self-service from other types of service only by its reliance on technology, with high activity on the part of the customer and low activity on the part of the service provider. This 'high tech, low touch' (Bitner, 2001; 
Glusko, 2012) distinction may no longer be so clear-cut (Scopula, 2011; Wunderlich et al., 2013). However, it is still relevant to note the level of activity that is required from the customer in obtaining the services. Without this active participation, the services are not available, and there is no real alternative. That participative interaction of the customer with the technology is the only means of obtaining the services. Customers must be willing, and able, to engage with the services.

Self-service is itself becoming more ubiquitous, reaching wider and deeper into all types of services (Rogers et al., 2007). Indeed, following the classification of Spohrer et al. (2010), we can enumerate self-services located within a) systems that move, store and process, where we find self-services established in systems for transportation, waste recycling, food and product distribution; b) services that are connected with health, education, finance, tourism, retail and leisure and c) services that govern and serve the public, such as self-service in filling in tax returns online, obtaining and renewing official documents (licences, passports) getting information, etc.

One of the most striking examples can be seen in airport customer management which is $80 \%$ self-services. Here, in the space of a few years, travellers have been channelled into doing their own ticket purchasing, seat allocation and check-in; luggage labelling and weighing; boarding pass scanning, as well using automatic booths for immigration checks.

\section{Self-services and e-Accessibility}

In simple terms, self-services means that there is no human intermediary to help with service provision. The older 'technology-mediated' touchpoint view implies that self-service is one option, and that human mediated service is also available. In many cases, self-services are evolving and becoming an integral part of the overall service, if not 'the service'. Firstly, often there are no alternatives to self-service; and secondly, if there are alternatives, they are not well supported and are inferior to the self-service option. As an example, there may be a 'call for assistance' button on a self-service terminal. This is not an alternative way of obtaining the service, but for use when the machine malfunctions or a mistake is made. Often its only result is to connect the caller with a service employee who is remotely located. Again, currently, airline passengers who choose to check in at the airport with human agent do not have the same access to seat allocation as passengers who have used self-service facilities. Finally, there are self-services for which there is no non-technology mediated equivalent. Recommender systems and social media offerings are a case in point of self-services that are 'the service'.

The question arises, what happens when these self-services are inaccessible or unusable by customers. Since the cost savings from "enticing customers to serve themselves" (Bitner \& Brown, 2006) can be extremely large, there is an extensive management and marketing literature that examines consumers' intentions to adopt self-service technologies . In demographic studies, the investigators typically study age, gender, education and income, while among the traits they distinguish: technology anxiety; need for interaction, (meaning people's desire to interact with person rather than with a machine); and openness to technology innovation (Meuter et al., 2000, 2005; Bitner et al., 2010, Wang et al., 2010). Some interesting insights emerge., People value competence in using the self-service technologies, not just because of the service benefits, but because of the feeling of selfachievement. It helps them feel independent and able to function within society, giving a feeling of self efficacy and of "being able to cope in the modern world" (Wang et al., 2013).

A range of reasons have been cited for customers rejecting self-services, from technophobia and techological illiteracy, to feeling self-conscious. Other reasons are due to extreme difficulties faced by some people with disabilies or age-related impairments or other 
inabilities to use these machines or online applications, because of the lack of accessibility features.

The issue of designing for accessibility means that the design of products, systems and, indeed, the built environment, should be designed so that it does not exclude people with disabilities. The most familiar examples are architectural accommodations, such as elevators or ramps in buildings that facilitate those who use mobility aids, such as wheelchairs. Following the Design for All (ANEC, 2007) ethos, such accommodations are also of benefit to other groups of people: those with temporary disabilities, for instance using crutches; or those carrying heavy loads, or those with children in push chairs. Accessibility and Design for All are also extended to include eAccessibility which includes the accessibility of web content; of content offered by digital television; and services offered by self-service terminals (eAccess+ network, 2010).

We consider these to be representative human-centric design problems for independence and autonomy. Our particular area of concern is the provision of these services to vulnerable people.

\section{eAccessibility and Vulnerable people}

With the term 'vulnerable' we include:

- older people,

- people with sensory and/or mobility and/or dexterity impairments,

- people with cognitive impairments

- people with literacy problems, such as economic refugees, who may understand, but not read, the language of the host country,

- people in handicapping situations, such as a parent with a small child, or an adult child caring for an elderly parent.

The increasing numbers of vulnerable people is an acknowledged problem. Statistics for Europe, (Eurostat, 2012) show the percentage of the population over the age of 65 reaching as much as $20 \%$ in Germany, and is predicted to rise. More of the population is living with agerelated disabilities. Added to this, is the global movement of populations because of war, famine, economic downturn and climate change that is increasingly fuelling the economic refugee situation (Eurostat, 2011). Most countries in the 'developed world' live in a servicebased economy, where services operate in many different contexts (Glushko, 2010). At the same time, many countries are now requiring their citizens to use online and unmanned services, and are withdrawing traditional face-to-face services. For instance, in 2013 Greek citizens were required to submit tax returns online, the paper based forms are no longer accepted (GR Reporter, 2013). This increase in technology mediated self-service (Datatrend, 2009, Holman \& Buzek, 2012) in the public service sector implies dependence on SSTs or personal access to internet enabled devices. Yet, for the most part, these are out of reach for vulnerable populations because of technological and/or economic barriers. Thus reliance on this type of service can signify difficulties or even exclusion from direct access to services for large sections of the population.

\section{Problems of self-service terminals or kiosks and some solutions}

For the purposes of this paper, we concentrate on the type of public services that are most commonly available via self-service technologies. These services range from the simple, such as the purchase of a train ticket, to increasingly more complex interactions, such as filling in forms or obtaining customized information. These services can be accessed and delivered via 
self-service terminals (SSTs) or kiosks available in public spaces. Some of the problems that these kiosks present are:

- Wheelchair users may not be able to get close to the controls of the kiosk.

- For partially-sighted users, the print on the screen or the buttons may be too small or without sufficient contrast.

- People who are blind, with hand tremors or missing limbs have difficulties with touch screens unless accessibility features are included or alternative interaction modes are implemented

- People with literacy problems or older people may find that kiosks time them out, because they need longer to make the decisions asked for by the kiosk software.

Our research (Darzentas et al., 2013) into these problems has shown that they continue to exist and even proliferate due to a variety of factors. Some of these are lack of awareness of the extent of the e-accessibility issues; lack of voiced complaints from customers or from deployers of services that use SSTs; and fragmentation of the supply chain, meaning that it is difficult to understand who is responsible.. Manufacturers are under pressure to ensure that their products fulfill some minimum accessibility requirements (e.g. for height of screen and interface controls), but there is a plethora of standards, that do not always agree one with the other. Some of these are confined to certain business sectors: for instance, the regulations for ATMs do not cover SSTs for airports, although both types of machines have many userfacing characteristics in common.

Because of the technology involved, problems with self-services are often set down at the door of the domains of interface design, usability and ergonomics (Glushko, 2010) and left for them to deal with. This in its turn has generated a whole range of solutions for a range problems types. At one end of the spectrum, problems may lie in the design of the self-service terminal itself, where customers are not able to understand what is required at the interface, (what to press, what slots to use, in what order). Some technologically-based solutions to tackle issues mentioned above include 'contactless' interaction (Madrid et al., 2013); automatically sensing the screen height and screen proximity required by users (Hagen \& Sandnes, 2010); or enabling blind users to use touchscreens by means of gestures (Sandnes, 2012).

At the other end of the spectrum, another class of problems go beyond the SST to understanding the service. For instance, to use the SST in a public car park, the user needs to understand the particular parking service paradigm in use, (e.g. is it 'pay and display'? is it 'pay on exit'? How do I pay? Where do I pay? When do I pay, before I get in my vehicle, or on exiting driving my car?). Some current technological proposals to deal with these situations are suggestions for interaction with a virtual assistant (Martin et al., 2011), or even human mediated help, delivered via video communication with a remote service provider (Syrjanen et al., 2012).

In addition to interface familiarity or service knowledge, another problem increasingly seen is that of users making false assumptions from one system to another and having expectations that are not met. In such cases, providing more information about the self-service system and operation (locations and capabilities, and how the system works) is a necessary step that is actually rarely available. For example, many people expect a machine to accept several different types of payment, (e.g. cash and debit/credit card). If the machines only accept credit cards, this blocks non-card holders from using the service, for instance buying their train tickets. This can be disastrous for a traveller, especially when there is no other type of machine or human-mediated service available. Further, it is of immense value for those customers who have time to plan their interaction. This last category are often those users 
who have more difficulty than usual in accessing services: for instance, users of wheelchairs or people with other mobility restrictions, such as those travelling with small children or carrying heavy luggage.

Finally, a further development is that of the increase in use of personal devices to access self-services. These may be 'fixed', such as desk based computers, or 'mobile' such as smartphones and tablets. User proficiency with technology increases with these devices that are familiar to their owners, in turn encouraging uptake of self-services that can be performed using them. For example, many airport check-in systems allow mobile based e-boarding passes. At the same time, people who do not have personal device access are even more excluded from services that are deployed with the expectation that the majority of customers have smartphones and internet connections and are able to use them. Following the Design for All concept, it is important to have alternatives in place available for these populations.

From our research (Darzentas et al., 2013) into the accessibility and e-accessibility of self-service terminals, we have seen that just "fixing the access to the machine" or "making a web site accessible" can only achieve partial results. To achieve the desired result of including those excluded by current self-services deployment, a wider perspective is required. Systems thinking has the potential to offer ways to help reach this more holistic understanding of what is needed.

\section{Roles of Systems Thinking}

Generally speaking, systems thinking in design has currently evolved into a term which encapsulates a way of thinking about design as the "holon' which contains the problem understanding and description of situation of concern. For instance, the design of a product, will, in its 'holon', have to carry from the outset, the widest possible set of aspects, notions and ideas, as well as the relationships amongst them, into the design praxis. In the case of the design of a mobile phone, there is knowledge to be gathered and applied regarding functionality and materials, hardware, software and infrastructure. Beyond these activities, the design praxis should encompass every relevant part (subsystem) of the product's 'world'. That includes such things as its packaging, the characteristics of the market and the target group of users - including accessibility concerns and respecting cultural paradigms. It can include considerations of device familiarity and learning, in relation to the need or not of a manual or other ways of communicating with users. Although the mobile phone is a product, the importance of the 'services' the phone is to offer to the user, are a major part of the problem space. In its turn, a consideration of the services of the mobile phone go well beyond the functionality to send or to receive data, to the essence of understanding the various meanings that arise in enabling communication between people.

\section{A Self-Service Case}

Current approaches to dealing with the accessibility of public self-services, and promoting the inclusion of vulnerable people, are mostly based on extended human-centred and human computer interaction research as discussed above and as seen by the industry (NCR, 2010). While this leads to ideas and concepts that push forward the research and the technology, they are not always immediately implementable, or even if they are, cannot be expected to solve all the problems.. The researchers themselves realise that their solutions may be too costly, or too difficult to maintain in the high usage settings of a public kiosk [Hagen \& Sandnes,2010, Lonyai, 2012]. Further, as Hassendahl (2003) notes, an ATM with a task flow that is well designed from a usability point of view, may be frustratingly slow for an experienced user. From a systems thinking perspective, we can understand that reality has been treated in a piecemeal or reductionist manner. As an example, guidelines pertaining to the optimal height 
of screens for ATMs have led to a plethora of accessibility related standards that are contradictory amongst them, and none of them really tackle key issues. It is our belief that systems thinking offers far more reach and deeper thinking about both the product and the service to be designed as well as the relationships between and among all the stakeholders and that this will help the design of more satisfactory solutions.

Some properties of designed systems with SSTs have eventually been identified, or at least, given more importance, mostly via costly trial and error. They could have been in the designed system from the beginning if systems thinking had been used to drive the problem identification, understanding, and modelling. As an example, in ATM design, the overriding importance of the property of 'privacy' is now being given much more prominence. What this results in is that the design and locating of an ATM should accommodate customers' need for privacy. While it is understandable that in the implementation of these systems, many tradeoffs are made, for instance, cameras are installed for security reasons, although this means privacy is compromised. However, this is not the type of privacy violation that users object to, it is rather the violation of personal space (other users stand too close to them) and worse, not being able to keep other users in their peripheral vision, when the queue naturally forms behind them. In systems thinking, this property would have emerged as part of the customers' subsystem whose relationships with subsystems such as those of ergonomics; location/allocation and spatial architecture (for example) could have made the properties of privacy and safety surface at the outset of the design process, and before implementation of solutions. Although ATMs have been in existence for many decades, it was not until recently that designs gave emphasis to this need for privacy (IDEO 2010), and these are still not widely implemented.

More specifically, in our example of a design intervention "to improve the situation for all" as referred to above, the example is set in the financial services world and centred around bill payment machines. Bill payment machines are automatic self-service terminals that allow users to input cash for payment for bills of various types, typically for utilities, mobile phone services and credit cards. This suits customers who do not or cannot use online banking systems as well as holders of one-off bills. In addition, bill payment machines serve those who are typically 'unbanked' or 'underbanked'. These last categories include $25 \%$ of the population of the United States, and many populations in countries, such as Russia, where people do not trust the banking system (Hall, 2012). In this setting, a local bank manager and his superiors decided they needed to install more bill payment machines inside the branch bank building because of the high volume of use and the subsequent increase in customer queues.

However, just "throwing more machines at the problem" created many new problems, each having a set of consequences. For example, installing more machines meant that the space inside the bank was further restricted, and the waiting areas became more cramped. This led in turn to removing most of the customer seating. This was especially resented by the older members of the public. As a result of the conditions, some customers decided to take their custom elsewhere, so as to avoid the unpleasant situation. The number of customers was reduced, (and possibly the need for the extra machines also reduced, although this was not studied).

However, these were not the only consequences. As in many such cases there were unanticipated systemic effects that reached into other subsystems, such as the way the staff communicated across the bank floor. Thus, installing new machines also caused problems for staffing of the operation of the bank. For the bank managers, the new SSTs obstructed their line of sight. This was important because an essential duty was to monitor the minute-tominute assignment of staff and to direct staff positions. Staff are regularly deployed to different tasks depending upon demand, and directed to go to where they are most needed at 
any given time during the day: for instance moving between teller stations and customer query stations. As a retrospective 'fix', the designers installed CCTV (Closed Circuit Television) cameras trained on the positions of each member of staff, so that the bank managers could continue to monitor operations. However, this is a one-way communication system, so staff were no longer able to communicate non-verbally with their superiors, as they had done when they had reciprocal direct line of sight. This had meant that they were coresponsible for the need to move: they had seen the problem, could anticipate deployment instructions and already prepare to move to where they were needed. Furthermore, the CCTV cameras gave them the feeling they were being "spied upon". This led to resentment and bad feeling between the staff and managers and demands that the managers agree not to make use of the cameras. The whole story of this design intervention therefore represented, not just a loss of time and investment, but damage to staff-manager relations.

Thus, as can be understood, from an attempt to deal with the problem of servicing customer demand for more bill payment machines and reduce queuing, many new problems were created, that were more serious than those they had set out to fix. They led to disruptions in the bank's operations as well as both bank-customer relations and staff-management relations. It is also noteworthy that in all the description given above, the problem of the accessibility of the machines for customers did not even enter into the problem space. If it had been taken into account as well, the needs of vulnerable users could have also prevented some problems (e.g. the seating for the waiting users would not have been removed).

\section{The Contribution of Systems Thinking}

We contend that had a systems thinking approach been used, and had the situation been considered as a system, rather than an isolated problem of needing more SSTs to satisfy demand, the disruptions and negative consequences described above could have been avoided. Taking a systems thinking approach would have brought up the requirements and conflicts much earlier. In that way, the designers would have acquired useful dimensions of understanding about the situation and about both when and where it would have been really useful to know, before implementing 'solutions'.

Certain tenets of systems thinking offer thinking tools to designers and could be illustrated using the bill payment machine example. They are those to do with emergence, complexity, requisite variety and notions of second-order cybernetics.

Emergence refers to the appearance of a non-predictable behaviour or property in response to an event (such as the adding of bill payment machines in a small space) and how this might trigger wide-ranging effects. It is not easy to predict these, because of not being able to understand in advance the complex behaviour that results from the interaction of disparate elements. A systems thinking designer, aware of the concept of emergence, would know to look beyond the immediate intervention of 'more machines $=$ less queues', to try to anticipate undesirable forms of emergence. Instead, he might actively look for desirable emergences. For instance, as happened when SSTs were placed side by side, resulting in an emergent behaviour of users, who, instead of queuing one behind the other and 'minding their own business' changed behaviour. They began to actively seek help and advice from the person using the machine next to them, resulting in a type of peer-to-peer learning. This finding has been observed in airports and train stations, but was not designed in a priori.

In the case above, the need for reducing queues at the bill payment machines should not be seen as the only 'symptom' of the situation of concern, but part of a more complex situation where there is a move towards self-services, devolving onto the customer responsibility for routine tasks, and reserving the bank staff for more specialised work. Understanding these dimensions means taking account of the complexity inherent in each 
situation of concern, but not in an effort to isolate an area of intervention, but to better orient the intervention.

Linked to emergence and complexity, the notion of 'requisite variety' (Ashby 1958) holds that any successful system will have developed a number of strategies to overcome problems. Translated into the bill paying machine scenario above, it means that there are ways to pay bills other than by machines, as well as alternate ways to use the machines, and that generally, the alternatives are equivalent when possible, and flexibility is present so that the bill paying gets done 'one way or another' and that it is possible for customers with a range of abilities, as is normal in the 'general public'.

Finally, we briefly note the contribution coming from second order cybernetics (Glanville, Heylighen \& Joslyn, 2001). This concerns the position of the designers, who are normally considered the experts brought in from outside to suggest solutions, in short, they are observers. Again, in summary form, in second order cybernetics, there is a change from considering the observer as outside of a system (as in first order cybernetics), to being part of the observed system. The observers (although that is not now the correct term since they are part of what is being observed), by filtering their observations through their own perspective, influence what they report and what they 'know'. This means that the designers -along with the problem owners and the stakeholders- become part of the system they are studying. This 'being part of the observed system' must be considered when designing, with reflections upon both the limitations to understanding as well as the extra understanding that a designer's professional training brings. It also means that designers are 'co-designing' with the problem owners and stakeholders.

In our example, the designers who recognise that their own understandings of the 'inputs' and 'outputs' of the queues at bill paying machines are only what they themselves observe, are aware that other understandings are possible. In addition, collaboration and cooperation with the problem owners and other stakeholders brings in new understandings. For example, queue reduction may appear the goal of the design intervention, but perhaps increase in business transactions is another interpretation, i.e. more machines, more people, more business. Such interpretations lead to different orientations of the design intervention, for instance, removing some people-manned workstations or even moving to larger premises. Perhaps it even warrants a new paradigm of interaction with people-less banks that are remotely manned, expressly for fast transactions, much as we have ATMs situated far from any bank.

Designers who have learnt about systems thinking are in a position to use these tenets to frame their approach to design interventions and organise them in ways that are not available from other methods and methodologies. The paradigm of self-services and accessibility and the concerns it imposes has been chosen to push to the limits and illustrate the necessity for new thinking about how to deal with those concerns. The implications, in terms of designerly praxis and education, of the example of bill payment systems, against a background of service design, are discussed next.

\section{Discussion}

It is our view that systems thinking will help designers to sustain the richness required for providing robustness and acceptability, i.e. producing something which relates to the actual problem, and aids its proper resolution. If designers are systems thinkers they will be actively looking for emerging properties, which they will try to incorporate in the design solutions. Designers who are aware of systems thinking will understand the need to uncover and 'import' the complexity of the design problem. They will, as well, acknowledge the need for requisite variety (Godsiff, 2010) to provide the necessary power to confront and deal with as many situations and conditions of use as possible.. 
Awareness of the notion of second order cybernetics should also help designers to ground their own role in the process of design. Briefly, they are aware that they are part of the problem and part of the solution, and not observers, and can account for the influence this might have on the design process and outcome.

In addition to this claim about the power of systems thinking for design, we posit that it is particularly important now, in the context of designers being asked to intervene in more complex situations. Against the background of an emerging service science, systems thinking can support service design, and design in general, towards its grounding for research, education and praxis. This is especially so given that service design is increasingly occupying more space in the human-centric problems of the design world. In the past, in disciplines such as management, complexity, although recognised, was resisted. Hard management / operational research were increasingly seen as approaches that cannot easily contain humancentric problems. However, the introduction of management and soft operational research meant that reductionism and hard problem definition and formulation were gradually questioned (Robb 1986). As a consequence terms like 'ill structured', 'ill defined', and 'wicked problems' were used for problems that defy hard definition, i.e. mapping onto technical mathematically-definable spaces. As a result, consultants and researchers changed roles, from specialists offering solutions to be approved and corrected as a result of stakeholder's reactions, into facilitators for engineering consensus.

The inherent complexity of current design problems is, in general, increasingly acknowledged, but not always welcomed by practitioners who do not feel competent to deal with it. Yet, complexity is driving design research and it owes this position to the more widely acknowledged realisation that reductionist practices are not leading to sustainable solutions. If the problem space is torn apart in the name of (helpful) reductionism, then parts of the problem are destroyed and possibly gone forever. Instead, designers need to be able utilise the insights that come from retaining complexity, rather than decomposing it.

The acceptance of complexity as fundamental to design problem understanding and solving has introduced new designer roles such as that of the facilitator, as well as methods, approaches and techniques which are actually doing collaborative design and co-design, etc. As a part of service design, which is located in the architecting of the negotiation between service provider and service customer, it is unequivocally human-centric. This is particularly evident in service design, whose praxis is located in the architecting of the negotiation between service provider and service customer, and where technocratic solutions are not adequate to deal with the human elements involved, and the sheer scale of the problems.

Systems thinking can contribute considerably in providing a framework to ground service design and offer to it new thinking tools. This paper has demonstrated some of the 'design tools' that systems thinking could provide.

Finally, designers who are trained in this way will be naturally open to the input of other disciplines and able to deal with them. Thus, in the case of the service design in general and self-service based technologies in particular, systems thinking designers will possess the thinking tools and knowledge to add in to their existing methods and methodologies. For instance, these would help them to seek for and determine the variety of service demands. They will know to look for the variety of services that should be provided and of course what the SSTs should be able to deal with. For example, in our case of the accessibility needs of vulnerable people, including those with a disability, but also non-native speakers, for whom using a self-service kiosk may be difficult, or even impossible, they will increase the variety to accommodate them. Following the law of requisite variety, such needs, if recognised, can actually offer creative opportunities for designers that enhance the usability and accessibility of the SSTs and the services for everyone (Darzentas \& Darzentas, 2014). 


\section{Conclusions}

A number of important issues have been identified and presented in this paper in relation to service design for its grounding and praxis. These include the human-centric nature of problems; the welcoming and utilisation of their complexity; the necessity of recognition of emerging properties through a holistic view of design problems; the acknowledgment of the need of variety in design problem understanding and offered solutions; and a reframed understanding of the role of the designer.

These issues led us to argue for the establishing of systems thinking in the world of design and especially service design. It is claimed that systems thinking can contribute considerably towards the formation and establishment of a theoretical and application framework for design, one that is justified initially through acknowledging the inherent complexity in this type of design. The argument is that if complexity as a notion is recognised by designers together with a number of other tenets of systems thinking, then this enhances the chances of design praxis to succeed in producing robust design solutions. It also characterises and enforces the profile of designer in a positive way.

In addition it must be noted that design rests upon the horizontal platform of inter/ multi/transdisciplinary domains, the richness of which should be maintained and exploited, and this requires that problem complexity is operationally present. As mentioned above, this paper has already made the assumption that a pool of knowledge and experience is required from the designers in order for them to be able to cope with experience of viewpoints from different disciplines and the resulting complexity of the emerging design problems. For this reason, and because of this concern we posited the thesis that currently one of the best ways to define and support a useful framework is the inclusion of systems thinking in design, especially now that service design is developing so rapidly and asked to intervene in such complex problems. In the same context, we share the concern about the theoretical identity of service science and its role in the future of service design. Given the rich disciplinarity of service science, service design should be expected to feed from that source.

This paper adopted the thesis that every artefact which results from design praxis, coexists with the resulting overall service design. This is how the example used here, i.e. selfservice, is considered being systemically designed as a service design, designed together with the 'touchpoints' (Bitner, 2001) of the system such as the SSTs or other delivery mechanisms.

Our example case of accessibility highlights the importance of the use of systems thinking. Particularly in the case of accessibility of the self-services, there is an irrevocableness that cannot be denied. Technology for public use, if designed appropriately, has the power to enable many vulnerable people who otherwise cannot participate in and enjoy these services. It is also a paradox that these systems are, perhaps, of more use to people who cannot easily use systems in a traditional manner because of, for instance, difficulties in mobility. On the negative side, badly designed and inaccessible technology and services also have the power to further disable, disenfranchise and reduce their autonomy if not designed in a holistic manner. Using systems thinking to deal with this problem, directs designers to consider accessibility needs as a result of utilizing notions such as requisite variety and emerging properties. It offers them the opportunity to make the accessibility, usability, and ultimately the usefulness of self-services and their offering more representative of all citizens' needs, being co-created with and for them. 


\section{John Darzentas}

Professor \& Head of Department

University of the Aegean, Department of Product and Systems Design Engineering idarz@aegean.gr

\section{Jenny S. Darzentas}

Lecturer

University of the Aegean, Department of Product and Systems Design Engineering jennyd@aegean.gr 


\section{References}

Ackoff, R.L. (1974). Redesigning the future: A systems approach to societal problems. New York: Wiley.

ANEC. (2007). Updated ANEC policy statement on Design for All. European Association for the Co-ordination of Consumer Representation in Standardisation, AISBL. Technical Report ANEC-DFA-2007-G-043rev. Brussels.

Arnellos, A., Spyrou, T., Darzentas, J. (2006). Exploring creativity in the design process: A systems-semiotic perspective. Cybernetics and Human Knowing, 14(1), 37-64.

Arnellos, A., Spyrou, T., Darzentas, J. (2007). Cybernetic embodiment and the role of autonomy in the design process. Kybernetes, 36 (9/10), 1207 - 1224.

Ashby W.R. (1958). Requisite variety and its implications for the control of complex systems, Cybernetica, 1(2), 83-99.

Bayazit, N. (2004). Investigating design: A review of forty years of design research. Design Issues, 20 (1), 16-30.

Bausch, K.C. (2001). The emerging consensus in social systems theory. Kluwer/Plenum.

Bitner, M.J. (2001). Self-service technologies What do customers expect? Marketing Management, 10(1), 10-1.

Bitner, M.J. \& Brown, S.W. (2006). The evolution and discovery of services science in business schools. Communications of the ACM, 49(7), 73-78.

Bitner, M.J., Zeithaml, V.A. \& Gremler, D.D. (2010). Technology's impact on the Gaps model of service quality. In P.P. Maglio et al. (Eds.) Handbook of Service Science: Research and Innovations in the Service Economy (pp. 197-218). London: Springer.

Brown, T. (2008). Design thinking. Harvard Business Review June, 1-9.

Cameron, F. \& Mengler, S. (2009). Complexity, transdisciplinarity and museum collections documentation, Journal of Material Culture, 14(2), 189-218.

Castro, D., Atkinson, R. \& Ezell, S. (2010). Embracing the Self-Service Economy. Information Technology and Innovation Foundation. Available at SSRN 1590982.

Charnley, F. and Lemon, M. (2011). Exploring the process of whole system design. Design Studies, 32, 156-179.

Checkland, P. (1981). Systems thinking, systems practice. Chichester, UK: John Wiley \& Sons Ltd.

Checkland, P. (2000). Soft Systems Methodology: A thirty year retrospective. Systems Research, 17, 11-58

Cross, N., Christiaans, H. \& Dorst, K. (1994). Design expertise amongst student designers. Journal of Art and design Education, 13(1), 39-56.

Darzentas, J. \& Darzentas, J.S. (2013). On the role of systems thinking in design and its application to public self-services. In B. Sevaldson \&, P. Jones (Eds.), Symposium Proceedings: Relating Systems Thinking and Design 2013 (RSD2): Emerging Contexts for Systemic Design, Oslo, Norway.

Darzentas, J.S. \& Darzentas, J. (2014). Accessible self-service: a driver for innovation in service design? Proceedings of service design and Innovation: Service Futures (ServDes2014) retrieved from http://www.servdes.org/wp/wp-content/uploads/2014/06/Darzentas-JS-Darzentas-J.pdf

Darzentas, J.S., Petrie, H.L. \& Powell, C. (2013). Universal design of self service terminals. In Skavlid, S., Olsen H.P. \& Haugeto, A.K. (Eds.).Trends in Universal Design (pp. 90-96). Oslo: The Delta Centre. Retrieved from http://issuu.com/hkre/docs/bufd_antologi_1113_web

Datatrend Technologies Inc. (2009). Creating a self-service world: how self-service kiosks are helping customers and benefiting businesses retrieved from http://www.datatrend.com/library/CreatingaSelfServiceWorld-0610.pdf

Dubberly, H. (2008). Design in the Age of Biology: Shifting from a Mechanical- Object ethos to an OrganicSystems ethos Interactions ACM September-October pp35-41.

eAccess+ (2010-2013) The eAccessibility Network. www.eaccessplus.eu

Eurostat (2011) "Migrants per 1000 Inhabitants, retrieved from http://epp.eurostat.ec.europa.eu/statistics_explained/index.php/Migration_and_migrant_population_stati stics 
Eurostat. (2012) Population Structure and Aging. Retrieved from http://epp.eurostat.ec.europa.eu/statistics_explained/index.php/Population_structure_and_ageing

Flood, R .L.,\& Jackson M.C. (1991) Creative problem solving: Total systems intervention, Wiley.

Forlizzi, J. (2008). The Product Ecology: Understanding Social Product Use and Supporting design Culture. International Journal of design 2(10), 11-20

Glanville, R. (2004) The purpose of second-order cybernetics, Kybernetes, 33, (9/10) pp.1379-1386.

Gloppen, J. (2011) The Strategic Use of service design for Leaders in Service Organizations FORMakademisk 4(2), 3-25.

Glushko, R.J. (2010) Seven Contexts for Service 'System design in P.P. Maglio et al. (eds.), Handbook of Service Science: Research and Innovations in the Service Economy, Springer (pp.219-249.)

Glushko, R.J. (2012) Describing Service Systems Human Factors and Ergonomics in Manufacturing and Service Industries, 23 (1), 11-18.

GRReporter, 2013 retrieved from http://www.grreporter.info/en/tax_pains_2013/9361

Godsiff, P. (2010) Service Systems and Requisite Variety Service Science 2(1-2) 92-101.

Hagen, S. and Sandes, F.E. (2010) Towards accessible self-service kiosks through intelligent user interfaces Personal Ubiquitous Computing 14, 715-721.

Hassenzahl, M (2003) The Thing and I: Understanding the relationship between the user and the product, Blythe, M.A., Monk, A.F., Overbeeke, K. \& Wright, P. (eds) Funology: From Usability to Enjoyment Kluwer Academic Publishers Netherlands, 31-42.

Hall, C. And Wheeler, E. (2012) Billpay: Kiosks Offer Benefits to the Bottom Line, Networld Alliance, retrieved from http://www.kioskmarketplace.com

Heylighen, F. \& Joslyn, C. (2001) Cybernetics and Second-Order Cybernetics, R.A. Meyers (ed.), Encyclopedia of Physical Science \& Technology (3rd ed) Academic Press, New York, available from http://pcp.vub.ac.be/Papers/Cybernetics-EPST.pdf

Holman, L. and Buzek, G. (2012) Market Study: 2012 North American self-service kiosks, KioskMarketplace, retrieved from www.ihlservices.com/ihl/public downloads/pdf5.pdf

IDEO (2010) Redefining self-service banking for the BBVA group retrieved from http://www.ideo.com/work/redefining-self-service-banking-for-bbva/

Jonas, W. (2007) Research through DESIGN through research: A cybernetic model of designing design foundations, Kybernetes, 36 (9/10), pp.1362-1380.

Jonas, W. (2011) A Sense of Vertigo, design thinking as General Problem Solver in Proceedings of Endless End, Proceedings 9th European Academy of design International Conference (EAD09) retrieved 13 October 2012 at http://www.transportation-design.org/cms/upload/DOWNLOADS/EAD09.Jonas.pdf

Jegou, F., \& Manzini, E. (2008) Collaborative services. Social innovation and design for sustainability, Milan Polidesign.

Klein, J.T. (2004) Prospects for transdisciplinarity Futures 36, 515-526.

Liem, A. (2012) Teaching strategic and systems design to facilitate collaboration and learning, FORMakademisk, 5(1), 29-48.

Lonyai, K. (2012) Commentary; A Harsh Reality for Kiosks, Kioskmarketplace Online Magazine $14^{\text {th }}$ August 2012, http://www.kioskmarketplace.com/press-releases/commentary-a-harsh-reality-for-kiosks/

Love, T. (2002) Constructing a coherent cross-disciplinary body of theory about designing and designs: some philosophical issues design Studies 23 pp.345-361.

Madrid, R.I., Turrero, M. \& Ortega-Moral, M.(2013) Applying Human-Centred design to Create a Collecting Tool of Needs and Preferences for the Personalisation of ATMs Assistive Technology: From Research to Practice 33,.380-385.

Maglio, P.P.; Srinivasan,S.; Kreulen, J.T.; Spohrer, J. (2006) Service systems, service scientists, SSME, and innovation Communications of the ACM, July 2006 49(7), 81-85.

Manzini E., Vezzoli C., Clark G. (2001) Product-Service Systems. Using an Existing Concept as a New 
Approach to Sustainability, design Research 1(2).

Martin, C. J., Archibald,·J., Ball L. \& Carson, L. (2011). Towards an Affective Self-services Agent. In Kudlka, M., Pokorný, J., Snášel, V., Abraham, A. (Eds.) Proceedings of the Third International Conference on Intelligent Human Computer Interaction (IHCI 2011) (pp.3-12) Prague, Czech Republic, August 2011.

Mele, C. Pel, J. \& Polese, F. (2010) A Brief Review of Systems Theories and Their Managerial Applications Service Science 2(1/2), 126-135.

Meroni, A. \& Sangiorgi, D. (2011) Design for services. Surrey, Gower Publishing Ltd.

Meuter, M. L., Ostrom, A. L., Roundtree, R. I., \& Bitner, M. J. (2000). Self-service technologies: Understanding customer satisfaction with technology-based service encounters. Journal of Marketing, 64, 50-64.

Meuter, M.L. Bitner, M.J. Ostrom, A.L. and Brown, S.W. (2005). Choosing among alternative service delivery modes: an investigation of customer trial of self-service technologies Journal of Marketing 69(2), 6183.

Moore, M.G., \& Kearsley, G. (1996/2005). Distance education: A systems view. Thomson/Wadsworth.

NCR (2010) Contemporary Interface Design for Self-Service An NCR White Paper available from www.ncr.com/servicesNelson, H.G. and Stolterman, E. (2002/2012) The design Way: Intentional Change in an Unpredictable World: Foundations and Fundamentals of design Competence. Educational Technology Publications.

Ng, C.L., Maull, R \&Yip, N. (2009) Outcome-based contracts as a driver for systems thinking and servicedominant logic in service science: Evidence from the defence industry European Management Journal, 27, 377-387.

Ng,C.L. \& Andreu, L.(2012) Editorial Special Issue: Research perspectives in the management of complex service systems European Management Journal 30, 405-409.

Nicolescu, B. Manifesto of Transdisciplinarity, State University of New York (SUNY) Press, New York, 2002, (transl byVoss, K.-C.)

Nicolescu, B (Ed.) (2008) Transdisciplinarity - Theory and Practice, Hampton Press.

Norman, D.(2009) The Way I See It systems thinking ACM Interactions 16(5) Sept-Oct 2009.

OECD (1972) Interdisciplinarity: Problems of Teaching and Research in Universities. Paris, OECD.

Pourdehnad,J., Wexler, E.R. \& Wilson, D.V. (2011) Systems and design thinking : A Conceptual Framework for Their Integration Proceedings of the 55th Annual Meeting of the International Society for the Systems Science pp 807-822.

Riis, K. (2013) A systems theory perspective on the relationship between practice and research in the making disciplines FORMakademisk 6(2) Art.7 1-13.

Robb, F.F. (1986) Operational Research and General systems thinking European Management Journal 4(1),5562.

Rogers, J., Birnie, S. \& Pengelly, J. (2007) Self-service Revisited International Conference on Engineering and Product design Education retrieved from www.TheDesignSociety.org

Sage, A.P. Systems Engineering. Wiley IEEE, 1992.

Sandnes, F.E., Tan, T. B., Johansen, A., Sulic, E., Vesterhus E., \& Iversen, E. R. (2012) Making touch-based kiosks accessible to blind users through simple gestures, Universal Access in the Information Society, 11(4), 421-431.

Sangiorgi, D. (2010) service design Research Pioneers: An overview of service design research developed in Italy since the '90s design Research Journal, 10(1), 26-59.

Scupola, A. (2011) Understanding E-Services, Self-services and Mobile Communications: Past Research and Future Directions, Preface to Developing Technologies in E-Services, Self-Services, and Mobile Communication: New Concepts IGI Global.

ServDes 2014 http://www.servdes.org/conference-2014-lancaster/

Sevaldson, B.(2010a) Discussions \& Movements in design Research A systems approach to practice research in design FORMakademisk, 3(1), 8-35. 
Sevaldson,B. (2010b) GIGA-Mapping: Visualisation for complexity and systems thinking in design in Proceedings of Nordic design Research Conferences Making design Matter available from http://ocs.sfu.ca/nordes/index.php/nordes/2011/paper/view/409

Simon, H. (1969) The Sciences of the Artificial MIT Press.

Spohrer, J., Golinelli, G.M., Piciocchi, P., \& Bassano, C. (2010) An Integrated SS-VSA Analysis of Changing Job Roles Service Science 2 ((1-2) 1-20.

Syrjänen A-L, Sihvola V, Kuutti K \& Vilmunen R (2012) Human-to-human interfaces for remote service kiosks the potential of audiovisual communication. Proceedings of the 7th Nordic Conference on HumanComputer Interaction (NordiCHI) 12. 288-297.

Valtonen, A. (2010) Is systemic design the next big thing for the design profession? Proceedings of design Research Society Conference 2010 retrieved January 2014 from http://www.designresearchsociety.org/docs-procs/DRS2010/PDF/121.pdf

Vargo,S.L. Maglio, P.P. \& Akaka, M.A (2008) On value and value co-creation: A service systems and service logic perspective. European Management Journal 26(3), 145-152.

von Bertalanffy, L., (1974) Perspectives on General System Theory E Taschdjian (Ed). George Braziller, New York.

Wang, C, Harris, J. Patterson, P. (2010) Customer choice of self-service technology: the roles of situational influences and past experience, Journal of Service Management 23(1), 54-78.

Wang, C, Harris, J. Patterson, P. (2013) The Roles of Habit, Self-Efficacy, and Satisfaction in Driving Continued Use of Self-Service Technologies: A Longitudinal Study Journal of Service Research 16(3), 400-414.

Wünderlich, N.V., Wangenheim, F. Bitner, M.J. (2013) High Tech and High Touch: A Framework for Understanding User Attitudes and Behaviors Related to Smart Interactive Services Journal of Service Research 16(1), 3-20.

\footnotetext{
${ }^{1}$ Here we were actually referring to the ancient Greek word ö $\lambda$ ov which means a «whole, containing many parts». The translation «holon» does not mean this (another case of «faux amis») (Perseus Digital Library, n.d.).
} 